\title{
The tribological characteristics of gas nitriding and surface texture 304 steel
}

\author{
Wengang Chen ${ }^{1, a}$, Xueyuan Liu ${ }^{1, b}$, Lili Zheng ${ }^{1, c}$ \\ ${ }^{1}$ College of Mechanics Engineering \& Transportation Southwest Forestry University, Kunming \\ 650224, China \\ aemail: chenwengang999@163.com, bemail: 690850094@qq.com, cemail: 28465623@qq.com
}

\author{
Keywords: 304 steel, Surface nitriding, Surface texture, Friction coefficient
}

\begin{abstract}
The diameter and spacing of $150 \mu \mathrm{m}, 200 \mu \mathrm{m}, 300 \mu \mathrm{m}$ stripe array on the surface of 304 steel were prepared by using M-DPSS-50 semiconductor laser device. Then, nitriding treatment on the textured surface was conducted by using well type gas nitriding furnace. The chemical composition, surface morphology and surface micro-hardness were measured by $\mathrm{X}$ ray diffraction, optical microscope and surface micro-hardness tester. The tribological properties of the composite modified surface were tested by MRTR microcomputer control multifunctional friction and wear testing machine. The results show that an regular textured surface was obtained. The surface micro-hardness of the gas nitriding treated sample reached 444.65HV0.1, which significantly higher than the 304 stainless steel substrate surface of 222.58HV0.1. The composite modified surface has anti-friction characteristics, but the anti-wear properties are not fully reflected because of ball diameter is smaller than the width of the texture.
\end{abstract}

\section{Introduction}

304 stainless steel is a widely used nickel chromium stainless steel with substrate for FCC Fe austenitic. the austenitic stainless steel has excellent corrosion resistance, good heat resistance, low temperature strength and mechanical properties, but it usually has low hardness, friction and poor wear performance. So it can not meet the composite performance requirements of both wear resistance and corrosion resistance in many cases $^{[1]}$. Generally it cannot be used to make a pair of friction components. In a limited application, the drive shaft or engagement with stainless steel as raw materials in the work process frequently occurs viscous or occlusion phenomenon because of the low surface hardness and strength ${ }^{[2]}$. Therefore, the tribological properties enhancement of 304 stainless steel surface and the application range prolongation has very important significance.

The traditional tribology theory consider that the more smooth contact surface cause the more small force of friction. But in recent years a large number of micro modeling on the friction surface research have been demonstrated which can effectively improve the surface tribological properties, and extensive attention has been paid to ${ }^{[3-6]}$. Previous studies have found that the surface texture can play the effect of friction reduction in almost all of the friction conditions ${ }^{[7-8]}$. In recent years, the research of laser processing on the surface of the material has been favored by the majority of researchers. The regular texture can be prepared on the surface of the material by using this method. And in the field of material surface chemical modification, surface nitriding is a good choice. there are three kinds of typical technology can achieve this kind of modified layer: gas nitriding, plasma nitriding and nitrogen ion injection process ${ }^{[9-12]}$. Gas nitriding with ammonia or nitrogen/hydrogen mixture as the nitriding media, through the physical and chemical interaction with the work piece surface to make the active nitrogen atoms through the surface into the austenitic stainless steel substrate. Gas nitriding process is relatively mature, equipment requirements are not high, the project cost is relatively cheap. Well type gas nitriding furnace is mainly used for gas nitriding of carbon steel parts, mold quenching and other heat treatment. The equipment is provided with a liquid dropping device, can also be carried out in gas nitrocarburizing (soft nitriding treatment).

According to this, this study used laser processing and well type gas nitriding technique to modify the surface of 304 steel. Then, the anti-friction and anti-wear properties of the composite 
modification surface was tested. This study has a great significance to the expansion of the application of 304 steel.

\section{Experimental materials and processes}

\section{Experimental materials and equipment}

The choice of matrix material in this study is 304 stainless steel plate. The experimental equipment and testing instruments used in the study include: M-DPSS-50 semiconductor laser marking machine, well type plasma nitriding furnace, the MH-6 micro-hardness tester, MRTR microcomputer controlled multifunctional friction and wear testing machine, YM200 optical microscope, D/MAX-Ultima+ X ray diffraction instrument.

\section{Experimental processes}

(1) A stripe texture with diameter and spacing of $300 \mu \mathrm{m}$ was prepared on the surface of 304 steel substrate via M-DPSS-50 semiconductor laser marking machine. The relevant parameters in the preparation: voltage for $15 \mathrm{~V}$, current for $8 \mathrm{~A}$, marking method for filling.

(2) Surface nitriding treatment. The textured surface and 304 steel substrate were nitrided at $580{ }^{\circ} \mathrm{C}$ for $3 \mathrm{~h}$ by using well type gas nitriding furnace. D/MAX-Ultima+ X X-ray diffraction and MH-6 micro-hardness tester was used to detect the phase composition and surface hardness. The micro-hardness measurement load of $0.98 \mathrm{~N}$, loading duration is $20 \mathrm{~s}$. In order to improve the measurement accuracy, 6 point measurements of each sample were conducted and then took the average.

(3) The tribological characteristics test. The friction and wear properties of the composite modification surface were detected by MRTR computer controlled friction and wear testing machine. The samples were 304 steel, nitriding 304 stainless steel smooth surface, and composite surface modification 304 steel. Experimental parameters: load for 9N, speed for $100 \mathrm{rpm}$ and friction time for $10 \mathrm{~min}$. The sliding mode was reciprocating linear movement with sliding speed of $5 \mathrm{~mm} / \mathrm{s}$ at $5 \mathrm{~mm}$ one-way distance under lubrication condition. $\mathrm{ZrO}_{2}$ ceramic ball (diameter of $4 \mathrm{~mm}$, relative hardness of HV1500) was chose as friction pair. The friction coefficient was recorded by the automatic recording system of the multifunctional friction and wear testing machine with $10 \mathrm{~s}$ interval time. The wear morphology of the specimen was detected by YM200 optical microscope.

\section{Results and discussion}

\section{Textured surface morphology}

Fig. 1 is the optical microscope morphology of textured surface before and after nitriding. It can be seen from Figure 1(a) , 1(b) and 1(c) that the surface of the laser textured 304 steel is very regular and clear. The width and spacing of the fringes are mostly 150um, 200um and 300um respectively. Figure 1(d), 1(e) and 1(f) are the texture surface topography after gas nitriding process. It can be clearly seen from the figure that the surface texture still maintain a clear pattern of texture characteristics and it not destroy the original surface texture, But the performance of the surface color change due to the change of material surface phase.

\section{Material properties of gas nitriding treatment}

Fig. 2 is XRD comparison chart of smooth 304 steel surface before and after gas nitriding. It can be seen from the figure that the original structure of 304 steel is austenitic stainless steel, and the nitriding layer is a single $\gamma \mathrm{N}$ phase after gas nitriding. Table 1 is the comparison $2 \theta$ value table before and after nitriding. It can be seen from the table that all diffraction peaks of $\gamma \mathrm{N}$ phase offset to low angle compared with the diffraction peaks of 304 stainless steel substrate. This is because that the crystal structure of the $\gamma \mathrm{N}$ phase is a face centered cubic structure with a higher deformation layer density and a lower twin layer density, the deformation layer caused by the nitriding makes the $\gamma \mathrm{N}$ phase $\mathrm{X}$ ray diffraction peak shift. 


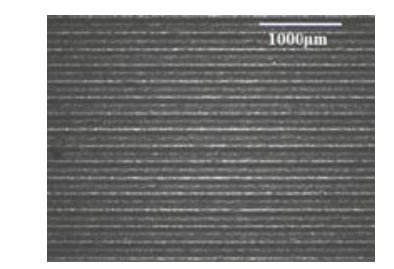

a $150 \mu \mathrm{m}$ stripe before nitriding

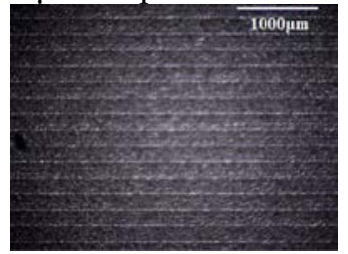

d $150 \mu \mathrm{m}$ stripe after nitriding

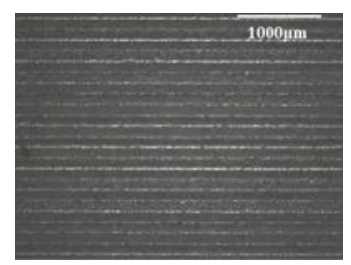

b $200 \mu \mathrm{m}$ stripe before nitriding

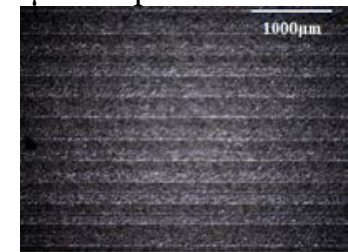

e $200 \mu \mathrm{m}$ stripe after nitriding

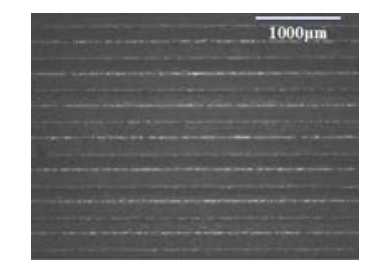

c $300 \mu \mathrm{m}$ stripe before nitriding

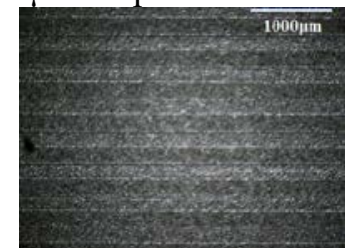

f $300 \mu \mathrm{m}$ stripe after nitriding

Fig. 1 The morphology of textured surface before and after nitriding

Table 1 The comparison $2 \theta$ value table before and after nitriding

\begin{tabular}{|c|c|c|c|c|}
\hline Crystal surface & 111 & 222 & 220 & 311 \\
\hline 304 steel & 43.62 & 50.66 & 74.74 & 90.60 \\
\hline Gas nitriding 304 steel & 43.56 & 50.52 & 74.4 & 90.24 \\
\hline
\end{tabular}

Table 2 is the surface micro hardness Comparison of the sample before and after nitriding. It can be seen from the table that the average micro-hardness of the 304 steel surface is $222.58 \mathrm{HV} 0.1$. And surface micro-hardness after gas nitriding reached $444.65 \mathrm{HV} 0.1$. This shows that the micro-hardness of the surface increases significantly after gas nitriding. This is due to the $\mathrm{Fe}-\mathrm{Cr}-\mathrm{Ni}$ three matrix atoms and interstitial nitrogen atoms which dissolved in the octahedral interstitial atoms form a saturated superhard expanded austenite $\mathrm{N}$ phase. It leading to high hardness, high resistance to fatigue performance and excellent resistance to wear anti corrosion performance.
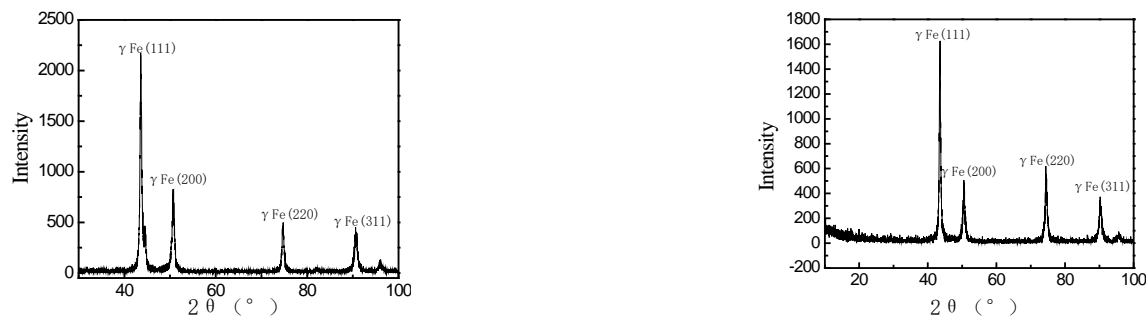

Fig. 2 Comparison of XRD before and after nitriding

Table 2 Surface micro hardness Comparison of the sample before and after nitriding (HV0.1 load 100g)

\begin{tabular}{|c|c|c|c|c|c|c|c|}
\hline Samples & 1 & 2 & 3 & 4 & 5 & 6 & Average \\
\hline 304 Steel & 210.0 & 231.8 & 224.0 & 224.6 & 226.2 & 218.9 & 222.58 \\
\hline Nitriding steel & 454.9 & 482.2 & 427.8 & 433.7 & 429.1 & 440.2 & 444.65 \\
\hline
\end{tabular}

\section{Friction and wear characteristics}

The friction coefficient curve of different surface is shown in Figure 3. The average friction coefficient of each friction pairs is shown in Table 3. It can be seen from Figure 3 that friction coefficient curve of 304 stainless steel substrate is higher in the initial stage. The reason of large fluctuations in the initial stage can be attributed to that this is the running in phase of the friction pair. The surface matrix wear amount is larger at this stage, which cause the sharp increase of the friction coefficient. while the friction coefficient curves of other samples are relatively stable and much less than the surface of the substrate. The friction coefficient of the smooth surface nitriding are slightly higher than the friction coefficient of the modified surface composite. Table 2 data show that the average friction coefficient of the surface of 304 steel substrate was significantly higher than that of the friction coefficient of the nitriding smooth surface. And the friction coefficient of the nitriding smooth surface is higher than that of composite modified surface. 


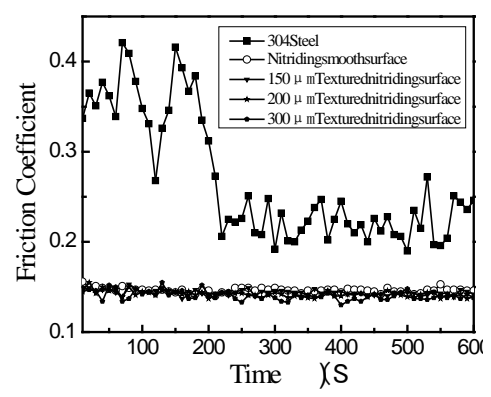

Fig. 3 contrast curve of friction coefficient

Figure 4 is wear surface morphology contrast diagram of different samples. It can be seen from Figure 4 that 304 stainless steel substrate surface appeared very obvious wear scar with about 402 $\mu \mathrm{m}$ width. The wear scar of nitriding smooth surface was very slightly and the width was about 128 $\mu \mathrm{m}$, which was far less than the 304 stainless steel substrate surface. The wear scar width of $150 \mu \mathrm{m}$, $200 \mu \mathrm{m}$ and $300 \mu \mathrm{m}$ composite modified surface was $147 \mu \mathrm{m}, 158 \mu \mathrm{m}$ and $196 \mu \mathrm{m}$. There was a certain increase compared with smooth surface. It can be seen from the figure that the 304 steel matrix had a clear breakthrough wear scar and the depth is deep, which is obvious abrasive wear characteristics. And the scar of the nitriding smooth surface and composite modification surface was relatively shallow and no abrasive wear morphology appeared. The above results showed that nitriding can significantly improve the 304 steel anti-friction and anti-wear properties. And the anti-friction performance of composite modification surface was more excellent, but the wear scar width was a certain increase compared with smooth surface. The reason for this phenomenon was that the surface hardness increased, so the wear resistance of the nitriding surface improved. At the same time, the oil can be better stored in the friction contact surface and the debris can be storage due to the appearance of the texture, which induced more excellent anti-friction characteristics. But there were frequently generated "Climbing" and "downhill" phenomenon when the upper test ball from the bottom to the upper part of the texture texture and the opposite during the test because of the contact width of the friction pair is greater than the width of the stripe texture. Which resulting in wear scar width more than smooth surface nitriding. The experimental results reveal that the friction pair contact diameter greater than the texture width, composite modification surface will has best friction reduction and anti-wear properties.

Tab.3 average friction coefficient

\begin{tabular}{|c|c|c|c|c|c|}
\hline Samples & 304Steel & $\begin{array}{c}\text { Smooth } \\
\text { nitriding surface }\end{array}$ & $\begin{array}{c}150 \mu \mathrm{m} \text { Textured } \\
\text { nitriding surface }\end{array}$ & $\begin{array}{c}200 \mu \mathrm{m} \text { Textured } \\
\text { nitriding surface }\end{array}$ & $\begin{array}{c}300 \mu \mathrm{m} \text { Textured } \\
\text { nitriding surface }\end{array}$ \\
\hline $\begin{array}{c}\text { Average friction } \\
\text { coefficient }\end{array}$ & 0.2925 & 0.1468 & 0.1447 & 0.1428 & 0.1415 \\
\hline
\end{tabular}

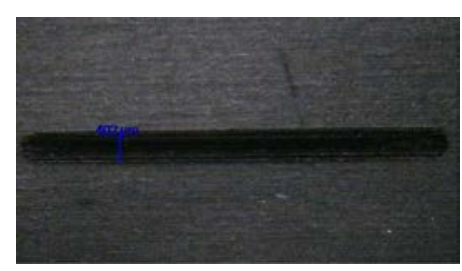

a 304 steel

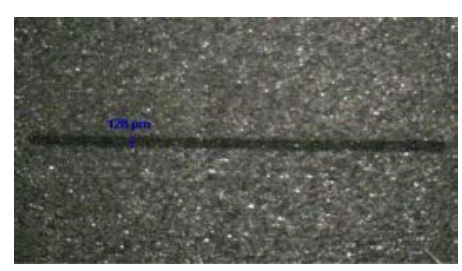

b Nitriding smooth surface

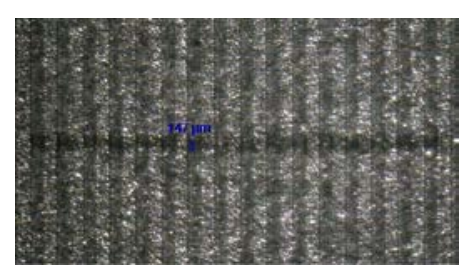

c150 $\mu$ m composite modification

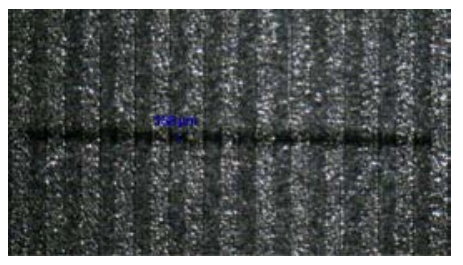

d 200 $\mu m$ composite modification surface

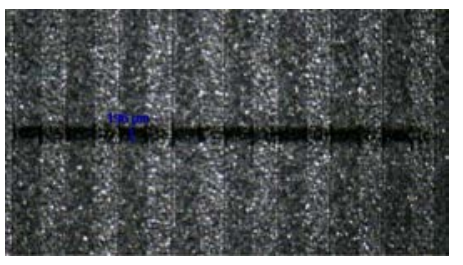

e 300 $\mu$ m composite modification surface

Fig. 4 Wear surface morphology contrast diagram 


\section{Conclusions}

A regular stripe texture was prepared on the surface of 304 steel substrate by laser in this study. Then, nitriding treatment on the textured surface via gas nitriding method. The following results were obtained through the experiment of friction under different conditions:

(1) The average micro-hardness of the 304 steel matrix surface was $222.58 \mathrm{HV} 0.1$, and the micro-hardness of the gas nitriding 304 stainless steel surface increased significantly, which reached 444.65 HV0.1.

(2) The anti-wear and friction reducing properties of the nitridin smooth surface are significantly better than that of the 304 substrate surface, which shows that the increase of the surface hardness of the 304 steel greatly improve the friction properties.

(3) The reducing friction performance of composite modified surface is better than that of nitriding smooth surface. The wear resistance of composite modified surface is worse than that of the nitriding smooth surface due to the contact diameter of the upper and lower samples. This shows that the texture of the diameter must satisfy the application requirements, so it can achieve a good effect of reducing friction and wear.

\section{Acknowledgement}

This research was financially supported by the "Application of basic research funded projects in Yunnan Province under Grant No. 2010CD067”.

\section{References}

[1] Qiang Tianjun. Tribological properties of $\mathrm{Ti}$ and $\mathrm{N}$ ions implanted 304 stainless steel[D]. Chengdu University of Technology, 2011.

[2] Liu Fuchun, Shi Yumin, Han Enhou. Development of surface treatment methods of stainless steel[J]. Journal of Shenyang University of Technology, 2001, 23(1):7-10.

[3] Grabon W, Koszela W, Pawlus P, et al. Improving tribological behaviour of piston ring-cylinder liner frictional pair by liner surface texturing[J]. Tribology International, 2013, 61(2): 102-108.

[4] Li Gan, Shen Mingxue, Meng Xiangkai, et al. An experimental study on tribological properties of groove-textured surfaces of 316L stainless steel[J]. Journal of Functional Materials, 2015, 46(2): 02033-02037.

[5] Andriy Kovalchenko, Oyelayo Ajayi, Ali Erdemir, et al. Friction and wear behavior of laser textured surface under lubricated initial point contact[J]. Wear, 2011,271: 1719-1725.

[6] Yang Chao, Liu Xiaojun, Yang Haidong, et al. Effect of the textured surface on the cutting performance of the tool and the friction property for the rake face[J]. Tribology, 2015, 35(2): 228-235.

[7] Huang Wei, Jiang Liang, Zhou Chuanxi, et al. The lubricant retaining effect of micro-dimples on the sliding surface of PDMS[J]. Tribology International, 2012, 52: 87-93.

[8] Shum P W, Zhou Z F, Li K Y. To increse the hydrophobicity and wear resistance of diamond-like carbon coatings by surface texturing using laser ablation process[J]. Thin Solid Films, 2013,544: 472-476.

[9] Christiansen T L,Somers M A J. Low-temperature gaseous surface hardening of stainless steel: the current status [J]. International Journal of Materials Research, 2009, 100(10): 1361-1377.

[10] Nakajima M, Nakamura Y, Suzuki K,et al. Effect of solution treatment after nitriding on fatigue properties in type 304 stainless steel [J]. International Journal of Fatigue,2014, 68: 103-110. [11] Mendes A F, Scheuer C J, Joanidis I L,et al. Low-temperature plasma nitriding of sintered PIM 316L austenitic stainless steel[J]. Materials Research-Ibero-American Journal of Materials, 2014, 17: 100-108.

[12] Femandes B B,Mandl S,Oliveira R M, et al. Mechanical properties of nitrogen-rich surface layers on SS304 treated by plasma immersion ion implantation[J]. Applied Surface Science, 2014, 310: 278-283. 